\title{
The effect of an extinction cue on ABA-renewal: does valence matter?
}

Citation for published version (APA):

Dibbets, P., \& Maes, J. H. R. (2011). The effect of an extinction cue on ABA-renewal: does valence matter? Learning and Motivation, 42(2), 133-144. https://doi.org/10.1016/j.Imot.2010.12.003

Document status and date:

Published: 01/01/2011

DOI:

10.1016/j.Imot.2010.12.003

Document Version:

Publisher's PDF, also known as Version of record

Document license:

Taverne

Please check the document version of this publication:

- A submitted manuscript is the version of the article upon submission and before peer-review. There can be important differences between the submitted version and the official published version of record.

People interested in the research are advised to contact the author for the final version of the publication, or visit the DOI to the publisher's website.

- The final author version and the galley proof are versions of the publication after peer review.

- The final published version features the final layout of the paper including the volume, issue and page numbers.

Link to publication

\footnotetext{
General rights rights.

- You may freely distribute the URL identifying the publication in the public portal. please follow below link for the End User Agreement:

www.umlib.nl/taverne-license

Take down policy

If you believe that this document breaches copyright please contact us at:

repository@maastrichtuniversity.nl

providing details and we will investigate your claim.
}

Copyright and moral rights for the publications made accessible in the public portal are retained by the authors and/or other copyright owners and it is a condition of accessing publications that users recognise and abide by the legal requirements associated with these

- Users may download and print one copy of any publication from the public portal for the purpose of private study or research.

- You may not further distribute the material or use it for any profit-making activity or commercial gain

If the publication is distributed under the terms of Article $25 \mathrm{fa}$ of the Dutch Copyright Act, indicated by the "Taverne" license above, 


\title{
The effect of an extinction cue on ABA-renewal: Does valence matter?
}

\author{
Pauline Dibbets ${ }^{\mathrm{a}, *}$, Joseph H.R. Maes ${ }^{\mathrm{b}}$ \\ a Clinical Psychological Science, P.O. Box 616, Maastricht University, 6200 MD Maastricht, The Netherlands \\ ${ }^{\mathrm{b}}$ Donders Institute for Brain, Cognition and Behaviour, Radboud University Nijmegen, The Netherlands
}

\section{A R T I C L E I N F O}

\section{Article history:}

Received 11 October 2010

Received in revised form

23 December 2010

\section{Keywords:}

Context

Extinction cue

Retrieval

Exposure

Valence

Renewal

Conditioning

\begin{abstract}
A B S T R A C T
The present human fear conditioning study examined whether the valence of an extinction cue has a differential effect on attenuating renewal that is induced by removal of the extinction context. Additionally, the study aimed to assess whether such attenuating effect is based on a modulatory or safety-signal role of the cue. In acquisition, extinction, and test stages of the experiment, human participants received pairings of human faces, presented against a particular background color, with the presence or absence of an aversive auditory stimulus. Experimental groups differed in the valence of a cue that was presented during extinction, in whether or not extinction took place against a different background color than present during acquisition and testing, and in whether the extinction cue was present or absent at test. The conditioned response consisted of auditory-stimulus expectancy ratings. It was hypothesized that a positively valued extinction cue yields faster extinction, stronger attenuation of renewal, and better transfer of its inhibitory power to non-extinguished stimuli than a negatively valued cue. All three hypotheses were confirmed, suggesting that the positive, but not the negative, cue had become a safety signal. The results were discussed in the framework of extinction-based exposure treatments.
\end{abstract}

(c) 2011 Elsevier Inc. All rights reserved.

Pavlovian fear conditioning is an influential model for the study of anxiety disorders (e.g., Mowrer, 1939). Perhaps the best-known example of fear conditioning is the Little Albert experiment by Watson and Rayner (1920). In this experiment, a 9-month-old boy received pairings of an initially neutral stimulus, a white rat, and an aversive event, the banging of a hammer on a steel bar. As a result of these pairings, little Albert not only reacted with a distress response (unconditioned response, UR) to the loud noise (unconditioned stimulus, US), but also showed signs of fear (conditioned response, CR) on presentation of the white rat (conditioned stimulus, CS), even if no noise followed.

A conditioned fear response can be extinguished by repeatedly presenting the CS without the US (Pavlov, 1927). Learning that the CS no longer predicts the occurrence of the US is not only important for adapting behavior; it also is the core principle of exposure therapy. In this therapy, patients with anxiety problems are exposed to the fear-eliciting stimulus/situation in order to abolish the conditioned fear response (Marks, Hodgson, \& Rachman, 1975; Öst, 1989, 1996, 1997). According to one well-developed and -evaluated theoretical framework, extinction does not erase the original CS-US association (feareliciting memory), but creates a competing CS-no US association (extinction memory), which inhibits the expression of the CR (Bouton, 2002, 2004). Which one of the two competing associations is expressed more strongly depends on the context in which the CS is presented: recall of the extinction memory on CS presentation shows a relative specificity to contexts that strongly resemble the extinction context, whereas other contexts favor retrieval of the fear-eliciting memory.

The most reliable and frequently used method to demonstrate that the CS-US association survives extinction is changing the context after extinction (Bouton, 2002, 2004). In the most common paradigm, ABA-renewal, fear conditioning occurs in

\footnotetext{
* Corresponding author. Tel.: +31 04338815 97; fax: +31043 3884155 .

E-mail address: Pauline.Dibbets@maastrichtuniversity.nl (P. Dibbets).
} 
context A, subsequent extinction in context B, and testing in context A. As a result of the context change after extinction, renewed responding to the $C S$ is observed. This reoccurrence of the $C R$ on $C S$ presentation is not limited to the acquisition context, but can also occur if the CS is presented in a novel context (ABC-renewal).

From a clinical point of view, a reoccurrence of the extinguished fear response is highly unwanted, implying a relapse. There are several ways to attenuate renewal, with the use of extinction cues being one of the most feasible methods (Havermans \& Jansen, 2003). An extinction cue can be defined as a distinctive cue (or element) that is part of the extinction context that, when presented outside the extinction context, can help to retrieve the extinction memory (Brooks, Vaughn, Freeman, \& Woods, 2004). In a series of animal conditioning experiments, Brooks and Bouton (1994) demonstrated that presentation of a cue stemming from the extinction context can indeed diminish renewal. When presented alone, the cue did not act as a conditioned inhibitor or excitor, suggesting a different, non-CS, function of the retrieval cue. The authors proposed that the extinction retrieval cue can help to disambiguate the meaning of the extinguished CS at test, by retrieving the memory of extinction. In line with these animal results, a few human studies also revealed attenuated renewal (induced by removal of the extinction context) by the presence of an extinction cue (Collins \& Brandon, 2002; Dibbets, Havermans, \& Arntz, 2008; Vansteenwegen et al., 2006).

One drawback of extinction cues functioning as retrieval cues is that the capacity that these cues have to diminish conditioned responding is limited to CSs that were explicitly trained and extinguished (Bouton, 2004; Dibbets et al., 2008). This implies little or no transfer of the inhibitory capacities to other CSs, that were not targets of treatment, eliciting the same unwanted conditioned responses as the targeted CSs. More generally, the issue of transfer to other, non-extinguished stimuli is important for differentiating between the putative functions that an extinction cue can acquire. The extinction cue can, theoretically, have at least two different roles: it can either function as a conditioned inhibitor or as an 'occasion setter' (Holland, 1989), which is closely linked to the retrieval-cue concept. If it functions as a conditioned inhibitor, the extinction cue predicts the absence of the US and has a 'safety signal' function. Such signal can easily transfer its inhibitory properties to other stimuli. If the cue serves as an occasion setter, the cue comes to control responding to a CS by signaling or activating a representation of a specific CS-US relationship stored in memory (Holland, 1983). Hence, an occasion-setting stimulus is not directly associated with the (non)occurrence of the US and, therefore, does not easily transfer its inhibitory powers to other stimuli (but see, Holland, 1989). From a clinical point of view, both functions have limitations. If the extinction cue is endowed with occasion-setting properties, little or no transfer to other non-extinguished CSs is expected. On the other hand, if the cue comes to function as a conditioned inhibitor, it can protect the CS from extinction (e.g., Lovibond, Davis, \& O'Flaherty, 2000) and removal of this safety signal can result in the immediate return of fear. Ideally, a cue's inhibitory potential would transfer to other non-extinguished stimuli, while still allowing 'true' extinction of target CSs to take place (implicating no return of conditioned responding upon its removal).

Dibbets et al. (2008) found that an extinction cue only acquired conditioned inhibitory properties if training, extinction, and testing all took place in the same context (implying that the cue was the only feature distinguishing between training and extinction). If training and testing took place in one context and extinction in another context, a distinctive cue present in the extinction context seemed to have acquired occasion-setting functions; no transfer of inhibitory potential to a nonextinguished CS was observed.

If the goal is to enhance the chance that an extinction cue's inhibitory power transfers to other non-extinguished CSs, one option might be to use a 'valid', extinction cue, that is, a cue that has some implicit or explicit history of association with positive outcomes, resulting in inhibitory properties. For example, danger signals, such as fearful facial expressions, when used as a CS, have been found to result in faster fear acquisition and slower extinction, whereas potential safety signals, such as happy facial expressions, result in relatively slow acquisition and rapid extinction (see for a review McHugo \& Smith, 1996). Even more importantly for present purposes, when a shock-associated, fear-provoking auditory CS was co-presented with happy faces during extinction, extinction was faster than when the CS was presented together with fearful faces (Lanzetta \& Orr, 1986). However, the authors did not examine whether removal of the facial stimuli resulted in a return of fear.

Given our lack of knowledge about the effect of the affective quality of an extinction cue on extinction and renewal, the present study had three primary aims. First, we wanted to examine the influence of the valence of an extinction cue (positive or negative) on extinction. Second, we aimed at exploring the capacity of these cues to generalize their fearattenuating properties to another, non-extinguished, stimulus. Third, we wished to assess the effect of the removal of these cues after extinction on the return of fear (renewal). We expected that, relative to a negative extinction cue, an extinction cue with a positive valence would promote faster extinction, show more generalization of response-attenuating powers to a non-extinguished stimulus, and more readily attenuate renewal. The latter implies that removal of a positive, but not a negative, cue should result in the return of fear, as it protects the CS from extinction.

\section{Methods}

In a separate pilot study $(n=50)$, we assessed the affective value of seven different symbols ( \&, (;), *, \#, @, !, and ?), using a paper visual analog scale with a maximum, positive, score of $100(0=$ very negative, $50=$ neutral, $100=$ very positive $)$. The most positively valued cue, the $(-)$ (mean: $87.52, S D: 10.55)$, and most negatively valued cue, the \# (mean: $38.10, S D$ : 14.53), were used as extinction cues. The - was rated significantly higher than the neutral value of $50, t(49)=25.16, p<.001$, whereas the \# was rated significantly lower than this neutral value, $t(49)=-5.79, p<.001$. 


\section{Participants}

A total of 183 students ( 31 male, 152 female; mean age: 21.68 years, $S D=4.06$ ) participated and received course credits or $\mathrm{a} € 5$ voucher for their participation. All students signed a written informed consent before onset of the experiment. They were randomly assigned to one of the eight experimental groups, with the restriction of an equal female/male distribution in each group.

\section{Apparatus}

\section{$A B A$ renewal task}

Three different photos of human faces, a Caucasian female, a Caucasian male, and a dark-complexion female, with a neutral facial expression $(1 \times \mathrm{h}$ : $355 \times 433$ pixels $)$ functioned as CSs. A loud scream $(2000 \mathrm{~ms}, 95 \mathrm{~dB})$ instantaneous rise time was presented binaurally through headphones and served as a US (see also Hamm, Vaitl, \& Lang, 1989). Two of the CSs were consistently followed by the US (CS1+ and CS2+), and the remaining stimulus was never paired with the US (CS3-). The CSs were presented against one of the two different background colors, orange or blue. These colors served as context, and either a smiley, "(-)", or a hash-symbol, “\#” (font size 90), on the computer screen functioned as the extinction cue. The role of stimuli (CS1, CS2, and CS3), background color (blue or orange), and stimulus order were fully counterbalanced, resulting in 12 versions per group. Only one version will be described for the remainder of the paper for the sake of clarity.

The US expectancy was measured on each trial by a visual analog scale (VAS) that was presented at the bottom of the screen below the stimuli and background. The indicator could be set anywhere between the far left (indicating "certainly no noise") and the far right end (indicating "certainly a noise") by clicking the left mouse button. The experiment was run on an IBM-compatible desktop computer and programmed with E-prime software (Psychology Software Tools, http://www.pstnet.com/).

\section{Questionnaires}

The Beck Anxiety Inventory (BAI, see Creamer, Foran, \& Bell, 1995) and the State and Trait Anxiety Inventory (STAI-DY, Van der Ploeg, 1982) were administered to assess trait and state anxiety. The BAI is a self-report questionnaire that contains 21 items measuring state anxiety. Responses can be scored on a 0-3 scale ranging from "not at all" to "severely", giving a score between 0 and 63. The STAI-DY contains two separate lists for state and trait anxiety. Each list contains 20 items and scoring is similar to the BAI (range per list 0-60). The BAI and STAI were administered to ensure that the trait and state levels of anxiety were similar across the experimental groups, as these can affect fear learning (see for a review, Bishop, 2007).

\section{Ratings}

The pleasantness of the US was measured both at the start and at the end of the experiment, using a paper VAS ( $0=$ highly unpleasant, 10 = highly pleasant). Additionally, the amount of 'startle' evoked by the US was measured at the start of the experiment. The participant also indicated the change in this US-evoked startle, as experienced at the end of the experiment, on a scale ranging from 0 to 10, with 0 representing a strong increase in the startle response, and 10 indicating a strong decrease. The pleasantness and experienced safety elicited by the CSs were only measured at the end of the experiment on a scale from 0 to 10 ( 0 = highly unpleasant/unsafe; 10 = highly pleasant/safe).

\section{Procedure}

The experiment consisted of an acquisition phase, an extinction phase, and a renewal test. Table 1 summarizes the

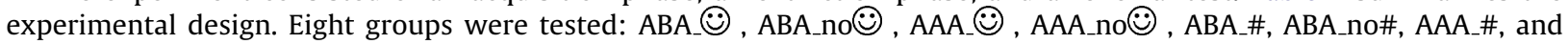
AAA_no\#. A and B symbolize the different contexts (orange and blue) during, respectively, the acquisition, extinction, and renewal test. The symbols '(-)' and '\#' indicate whether the cue was present (-) and \#) or absent (no:) and no\#) during the renewal test. Note that the extinction cue was presented throughout the entire extinction phase for all groups. For example, ABA_no\# indicates that this group received the acquisition in context A, the extinction in context B (plus extinction cue \#), and that the renewal test was performed in context A with no extinction cue present.

\section{Pre-conditioning}

After entering the experimental room, the participant was seated in a comfortable armchair and was given written information concerning the experiment. After reading this information and signing the informed consent, the participant filled out the BAI and STAI. Next, the experimenter started the experiment and an instruction screen appeared. This instruction encouraged the participant to detect the contingencies between the pictures and the (non)occurrence of the loud noise. Furthermore, a brief instruction about the use of the visual analog scale (VAS) was presented. Subsequently, three practice trials were presented using three different neutral faces (Asian males) that were not presented during the conditioning task. No USs were presented during these practice trials. After finishing the third practice trial, the US was presented twice and the participant was told that the scream should be loud and aversive, but not painful. If necessary, the volume of the US was adjusted on directions of the participant (only three participants asked for an adjustment). The participant rated the US (pleasantness and amount of startle evoked) and, subsequently, a screen appeared summarizing the task instructions. The 
Table 1

Experimental design.

\begin{tabular}{|c|c|c|c|}
\hline Group & Acquisition & Extinction & Renewal Test \\
\hline \multirow[t]{3}{*}{ ABA_: } & $\mathrm{A}[\mathrm{CS} 1+]$ & $\mathrm{B}[\mathrm{CS} 1-])$ & $\mathrm{A}[\mathrm{CS} 1] \odot$ \\
\hline & $\mathrm{A}[\mathrm{CS} 2+]$ & $\mathrm{B}[\mathrm{CS} 3-]$ & $\mathrm{A}[\mathrm{CS} 2] \bigodot$ \\
\hline & $\mathrm{A}[\mathrm{CS} 3-]$ & & $\mathrm{A}[\mathrm{CS} 3] \odot$ \\
\hline \multirow[t]{2}{*}{ ABA_no $\odot$} & $\mathrm{A}[\mathrm{CS} 1+]$ & $\mathrm{B}[\mathrm{CS} 1-])$ & $\mathrm{A}[\mathrm{CS} 1]$ \\
\hline & $\begin{array}{l}\mathrm{A}[\mathrm{CS} 2+] \\
\mathrm{A}[\mathrm{CS} 3-]\end{array}$ & B[CS3- $]$ & $\begin{array}{l}\mathrm{A}[\mathrm{CS} 2] \\
\mathrm{A}[\mathrm{CS} 3]\end{array}$ \\
\hline \multirow[t]{3}{*}{ AAA_: } & $\mathrm{A}[\mathrm{CS} 1+]$ & $\mathrm{A}[\mathrm{CS} 1-] \odot$ & $\mathrm{A}[\mathrm{CS} 1] \odot$ \\
\hline & $\mathrm{A}[\mathrm{CS} 2+]$ & $\mathrm{A}[\mathrm{CS} 3-] \odot$ & $\mathrm{A}[\mathrm{CS} 2] \odot$ \\
\hline & $\mathrm{A}[\mathrm{CS} 3-]$ & & $\mathrm{A}[\mathrm{CS} 3] \odot$ \\
\hline \multirow[t]{3}{*}{ AAA_no: } & $\mathrm{A}[\mathrm{CS} 1+]$ & $\mathrm{A}[\mathrm{CS} 1-] \odot$ & $\mathrm{A}[\mathrm{CS} 1]$ \\
\hline & $\mathrm{A}[\mathrm{CS} 2+]$ & $\mathrm{A}[\mathrm{CS} 3-] \odot$ & $\mathrm{A}[\mathrm{CS} 2]$ \\
\hline & $\mathrm{A}[\mathrm{CS} 3-]$ & & $\mathrm{A}[\mathrm{CS} 3]$ \\
\hline \multirow[t]{3}{*}{ ABA_\# } & $\mathrm{A}[\mathrm{CS} 1+]$ & $\mathrm{B}[\mathrm{CS} 1-] \#$ & $\mathrm{~A}[\mathrm{CS} 1] \#$ \\
\hline & $\mathrm{A}[\mathrm{CS} 2+]$ & $\mathrm{B}[\mathrm{CS} 3-] \#$ & $\mathrm{~A}[\mathrm{CS} 2] \#$ \\
\hline & $\mathrm{A}[\mathrm{CS} 3-]$ & & A[CS3]\# \\
\hline \multirow[t]{3}{*}{ ABA_no\# } & $\mathrm{A}[\mathrm{CS} 1+]$ & $\mathrm{B}[\mathrm{CS} 1-] \#$ & A[CS1] \\
\hline & $\mathrm{A}[\mathrm{CS} 2+]$ & $\mathrm{B}[\mathrm{CS} 3-] \#$ & $\mathrm{~A}[\mathrm{CS} 2]$ \\
\hline & $\mathrm{A}[\mathrm{CS} 3-]$ & & A[CS3] \\
\hline \multirow[t]{3}{*}{ AAA_\# } & $\mathrm{A}[\mathrm{CS} 1+]$ & $\mathrm{A}[\mathrm{CS} 1-] \#$ & $\mathrm{~A}[\mathrm{CS} 1] \#$ \\
\hline & $\mathrm{A}[\mathrm{CS} 2+]$ & A[CS3-]\# & $\mathrm{A}[\mathrm{CS} 2] \#$ \\
\hline & $\mathrm{A}[\mathrm{CS} 3-]$ & & A[CS3]\# \\
\hline \multirow[t]{3}{*}{ AAA_no\# } & $\mathrm{A}[\mathrm{CS} 1+]$ & A[CS1-]\# & A[CS1] \\
\hline & $\mathrm{A}[\mathrm{CS} 2+]$ & A[CS3-]\# & $\mathrm{A}[\mathrm{CS} 2]$ \\
\hline & $\mathrm{A}[\mathrm{CS} 3-]$ & & $\mathrm{A}[\mathrm{CS} 3]$ \\
\hline
\end{tabular}

Notes. A and B represent two different background colors, CS1, CS2, CS3 are three different conditioned stimuli; + indicates 'is followed by the US', - represents 'no US'. - or \# means that the extinction cue is present. Testing was conducted without the US.

experimenter checked whether all instructions were clear and whether the participant was able to correctly use the VAS and then left the room.

Acquisition phase

The acquisition phase was identical for all eight groups. The background color remained orange during the entire phase. The CS was presented at the center of the screen. Below the CS, at the bottom of the computer screen, a gray band was displayed containing the VAS. The text "certainly no noise" was displayed to the left of the VAS; to the right, the text "certainly a noise" was shown. Both the CS and the VAS remained visible until the participant's response. In case of CS1 and CS2 the US (2000 ms) was directly presented after termination of the CS (i.e., right after the VAS response). No US was presented after CS3. The intertrial-interval varied between 4 and $6 \mathrm{~s}$ (mean: $5 \mathrm{~s}$ ). Each CS was presented 8 times, resulting in 24 trials. CSs were pseudo-randomly mixed with the restriction that a CS was never presented more than twice in a row, and US-trials were never presented more than four times in succession. The next phase automatically started after the last trial, without interruption.

\section{Extinction phase}

For all ABA-groups, the background color switched to blue; for all AAA-groups the background color remained orange for the entire extinction phase. For all groups, CS1 and CS3 were presented 16 times each and no USs were presented. Stimulus order was pseudorandom with the restriction that a specific stimulus was not presented more than three times in succession. The extinction cue was presented during the entire extinction phase (-) or \#). The position of the cue varied across trials, but never overlapped the CS. Change in position occurred $4 \mathrm{~s}$ after termination of the CS. This procedure of repeated changes in position of the extinction cue was introduced to discourage configural learning ('merging' of background and cue and associating this merged stimulus with the absence of the US), to enhance the salience of the extinction cue, and to make this cue clearly different from the static 'contextual' background color ('ground') and target CSs ('figure'). The renewal test was presented without interruption after the last extinction trial.

\section{Renewal test}

All groups received the renewal test with the orange acquisition context present. For half of the groups, the extinction cue was present, ABA_(:), AAA_(-), ABA_\#, and AAA_\#, and for the other half, no cue was presented, ABA_no:; , AAA_no:) , ABA_no\#, and AAA_no\#. Each CS was presented once; the stimulus order during testing was completely counterbalanced. After finishing the last trial, the participant was requested to rate the CSs (pleasantness and safety) and the US (pleasantness and change in evoked startle). 
Criteria

Only the data of participants that mastered the task were used for analyses. Performance was labeled successful if the following criteria were met: (1) On the last acquisition trial, scores on the VASs for CS1 and CS2 needed to be at least $80 \%$, indicating a clear expectancy of the US; (2) Scores on the last acquisition trial of CS3 needed to be $20 \%$ or less, indicating that no US was expected; and (3) On the last extinction trial, both CS1 and CS3 ratings should be $20 \%$ or less, reflecting successful extinction. These criteria were used because testing for potential renewal is meaningless in the absence of adequate extinction, and examining extinction becomes meaningless in the absence of clear acquisition.

\section{Statistical analyses}

The BAI and STAI scores, the stimulus pleasantness and safety ratings, and the US-expectancy ratings were all analyzed using analysis of variance (ANOVAs and GLM repeated measures). Bonferroni corrections were used by adjusting the rejection criterion in case of multiple or pairwise comparisons. In case of violations of sphericity, Greenhouse-Geisser corrections were made. Possible differences between groups in gender distribution were analyzed nonparametrically. Effect sizes were expressed as partial eta squared, $\eta^{2}$. The standard rejection criterion was set at $p<.05$ throughout.

\section{Results}

The data from 38 participants were discarded from data analyses (see Table 2). Twelve of these participants were excluded because they did not meet the aforementioned criteria for successful acquisition and 26 participants because of unsuccessful extinction. The remaining 145 participants were 23 males and 122 females $(M$ age $=21.31$ years; $S D=2.36)$. The number of participants per group was: ABA_: $n=11$; AAA_- $n=19 ;$ ABA_\# $n=19$; AAA_\# $n=17 ;$ ABA_no: $n=18$; AAA_no@ $n=16$; ABA_no\# $n=21$; and AAA_no\# $n=24$. No significant differences between the eight experimental groups concerning age, BAI-, STAI-scores (state and trait), $F s<1.85, p s>.08$, or gender were detected, $\chi^{2}=3.19, p=.87$ (see Table 2 ).

\section{US-expectancy ratings}

\section{Acquisition}

The mean US-expectancy ratings induced by CS1, CS2, and CS3 are presented in Fig. 1. GLM repeated measures analysis, with stimulus type (CS1, CS2, and CS3) and trial (1 through 8) as within-subjects factors, was used to analyze the expectancy ratings of the acquisition phase. This analysis revealed a main effect of stimulus, $F(1.32,189.44)=2644.03, p<.001, \eta^{2}=0.95$, a main effect of trial, $F(3.84,552.96)=125.55, p<.001, \eta^{2}=0.47$, and a stimulus $\times$ trial interaction, $F(6.48,933.63)=117.42$, $p<.001, \eta^{2}=0.45$. Separate GLM repeated measures analyses of CS1, CS2, and CS3 with trial (1 through 8) as a withinsubjects factor indicated that the interaction was caused by the gradual increase in CS1 and CS2 ratings, and a decrease in CS3 ratings across trials, Fs $>54.01, p s<.001, \eta s^{2}>0.27$. A separate GLM repeated measures analysis on the data from the last acquisition trial, with stimulus (CS1, CS2, and CS3) as a within-subjects factor, revealed a main effect of stimulus, $F(1.10$, $158.09)=100953.7, p<.001, \eta^{2}=1.00$. Pairwise comparisons indicated that at the end of the acquisition phase, both CS1 and CS2 received higher ratings than CS3, $p s<.001$, but did not differ from each other, $p=1.00$.

These results confirm that the participants learned to differentiate between the CSs that were followed by the US and the non-reinforced CS.

\section{Extinction}

The US-expectancy ratings for CS1 and CS3 during the extinction phase are depicted in Fig. 2 (left side: the positive cue (-) ), right side: the negative cue (\#)). GLM repeated measures analysis, with stimulus (CS1 and CS3) and trial (1-16) as within-subjects factors and cue valence $(-;$ and $\#)$ and context switch as between-subjects factors, revealed a main

Table 2

Group means $(+S D)$ of the included participants.

\begin{tabular}{|c|c|c|c|c|c|c|}
\hline \multirow[t]{2}{*}{ Group } & \multicolumn{3}{|l|}{ Demographic } & \multicolumn{2}{|l|}{ STAI } & \multirow[t]{2}{*}{ BAI } \\
\hline & Age & $\mathrm{M} / \mathrm{F}$ & Excl & State & Trait & \\
\hline ABA_-्) & $20.45(0.41)$ & $0 / 11$ & 8 & $31.82(8.24)$ & $33.73(8.00)$ & $27.91(3.53)$ \\
\hline ABA_no & $22.91(3.40)$ & $3 / 15$ & 2 & $34.11(7.90)$ & $35.89(7.58)$ & $28.83(7.48)$ \\
\hline AAA_- & 24.45 (2.19) & $4 / 15$ & 2 & $31.00(7.23)$ & $32.21(7.59)$ & $25.47(2.70)$ \\
\hline AAA_no & $21.05(1.66)$ & $3 / 13$ & 4 & 31.25 (6.05) & $31.56(5.48)$ & $28.38(6.72)$ \\
\hline ABA_\# & $21.89(2.49)$ & $4 / 15$ & 7 & $32.47(5.02)$ & $36.79(7.14)$ & $27.95(4.52)$ \\
\hline ABA_no\# & $20.20(1.44)$ & $3 / 18$ & 5 & $34.50(7.97)$ & 36.17 (9.07) & $28.31(4.38)$ \\
\hline AAA_\# & $21.22(2.11)$ & $2 / 15$ & 8 & $34.29(9.86)$ & 36.32 (10.59) & $29.76(7.07)$ \\
\hline AAA_no\# & $21.44(2.75)$ & $4 / 20$ & 2 & $32.58(6.96)$ & $35.83(8.70)$ & $28.92(4.10)$ \\
\hline
\end{tabular}

Notes. $\mathrm{M} / \mathrm{F}=$ number of males and females, excl = number of excluded participants, STAI = State and Trait Anxiety Inventory, BAI = Beck Anxiety Inventory. 


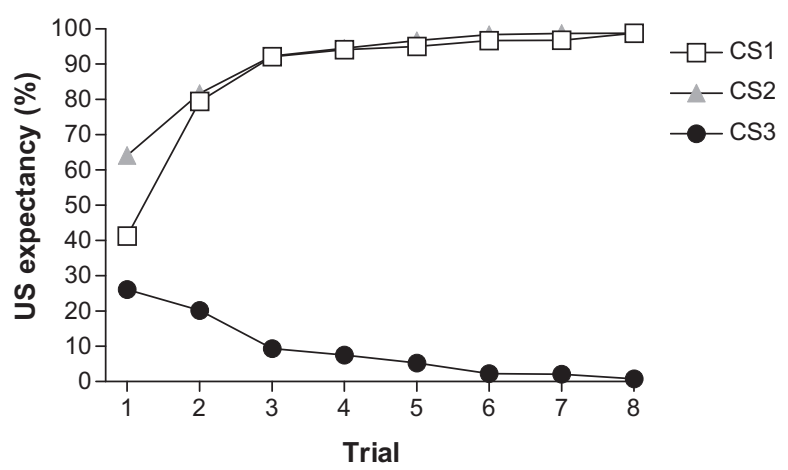

Fig. 1. Mean US-expectancy ratings evoked by CS1, CS2, and CS3 during the acquisition phase; $0 \%$ indicates that the shock is 'certainly not expected', whereas $100 \%$ indicates that the shock is 'certainly expected'.

Positive cue

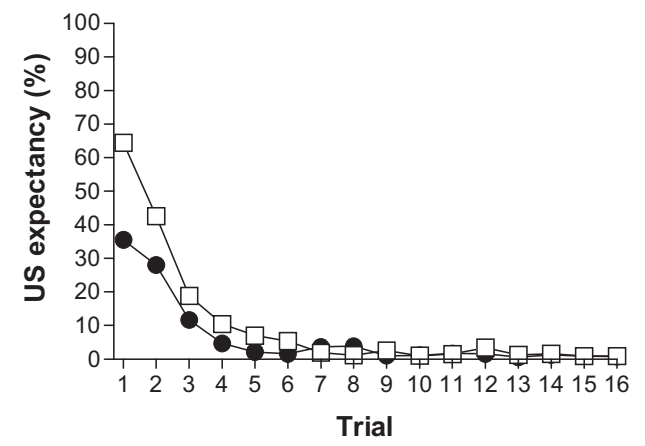

Negative cue

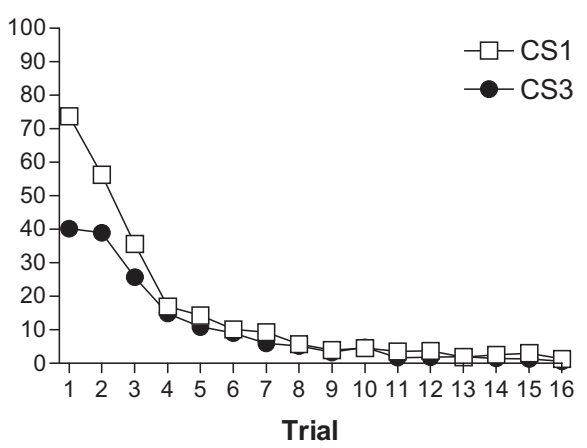

Fig. 2. Mean US expectancy ratings evoked by CS1 and CS3 during the extinction phase for the positive (:) and negative (\#) retrieval-cue conditions.

effect of stimulus, $F(1,141)=41.52, p<.001, \eta^{2}=1.00$, trial $F(4.84,682.01)=216.81, p<.001, \eta^{2}=1.00$, and cue valence, $F(1$, $141)=14.61, p<.001, \eta^{2}=0.97$. No main effect of context switch was observed, $F(1,141)=2.40, p=.12$. These results indicate that, overall, the ratings for CS1 were higher than for CS3, that the ratings declined across trials, and that the participants with the positive cue $(;)$ ) had lower US-expectancy ratings during the extinction phase than the participants with the negative cue (\#).

Additionally, a stimulus $\times$ trial interaction, $F(3.52,496.95)=16.90, p<.001, \eta^{2}=1.00$, and a trial $\times$ cue valence interaction, $F(4.84,682.01)=4.56, p<.005, \eta^{2}=0.97$, were observed. The analysis revealed no other significant interactions, Fs $<1.02$, ps $>$.39. The stimulus $\times$ trial interaction was caused by a decrease in the rating difference between CS1 and CS3 across the extinction phase. This difference in decline was analyzed using a repeated measures GLM, with the amount of discrimination between CS1 and CS3 (i.e., CS1-CS3) across trials (1 through 16) as a within-subjects factor. This analysis revealed a significant effect of trial, $F(3.54,510.15)=17.31, p<.001, \eta^{2}=1.00$, indicating that the difference between CS1 and CS3 declined as the extinction phase progressed.

As can be observed in Fig. 2, the trial $\times$ cue valence interaction was probably caused by the initial higher ratings on CS1 and CS3 for the negative cue $(\#)$ compared to the positive cue $(\odot)$ ) during the first half of the extinction trials. We, therefore, decided to split the extinction phase into two equal parts (i.e. trials 1-8 and trials 9-16) and ran two separate GLM repeated measures analyses, with stimulus (CS1 and CS3) and trial (1-8 or 9-16) as within-subjects factors and cue valence as a between-subjects factor. These analyses indeed revealed that it was only during the first part of the extinction phase that higher ratings were observed for the negative cue (\#) compared to the positive cue ( $(;), F(1,143)=17.83, p<.001, \eta^{2}=0.99$. No cue valence difference was observed for the second part of the extinction phase, $F(1,143)=2.22, p=.14$.

Figs. 1 and 2 suggest that there was only partial transfer of expectancy ratings from the acquisition to the extinction phase. A separate GLM repeated measures analysis, with stimulus type (CS1 and CS3) and trial (last acquisition and first extinction trial) as within-subjects factors revealed a main effect of stimulus, $F(1,144)=678.76, p<.001, \eta^{2}=1.00$, a main effect of trial, $F(1,144)=4.68, p<.05, \eta^{2}=0.58$, and a stimulus $\times$ trial interaction, $F(1,144)=183.26, p<.001, \eta^{2}=1.00$. The interaction was caused by a decrease in CS1 and an increase in CS3 ratings, GLM repeated measures, Fs $>88.31, p s<.001$, $\eta \mathrm{s}^{2}=1.00$. However, like at the end of acquisition, at the onset of the extinction phase CS1 still was rated higher than CS3, paired $t$-test, $t(145)=6.38, p<.001$, indicating a limited generalization decrement.

Finally, a separate GLM repeated measures analysis using the data from the last extinction trial (trial 16) with CS1 and CS3 as within-subjects factor, and cue valence as between-subjects factor, revealed that CS1 was still rated slightly higher 


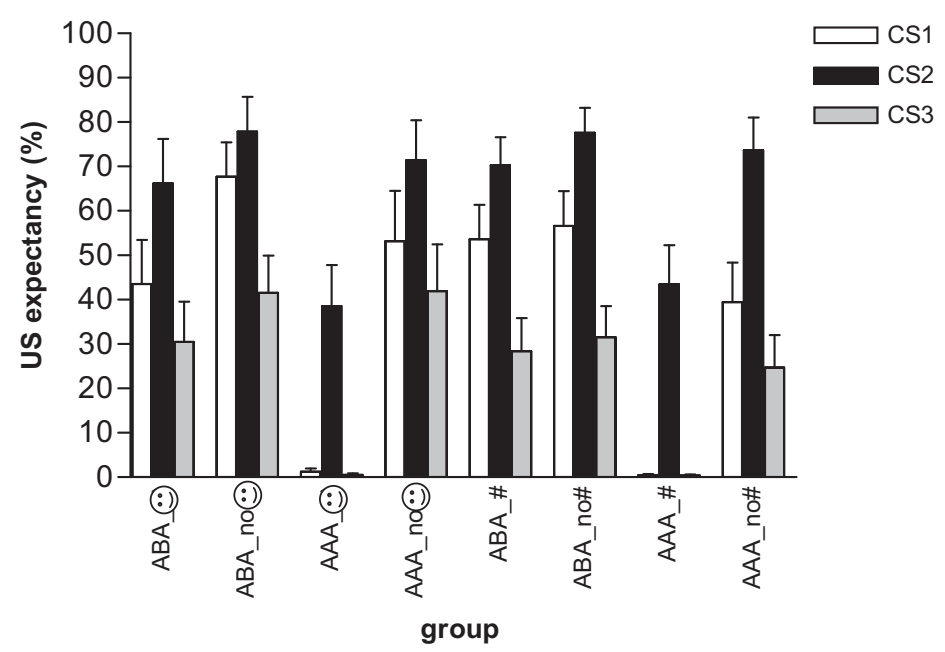

Fig. 3. Groups' mean US-expectancy ratings during the renewal test.

than CS3 $\left(1.15 \%\right.$ and $0.73 \%$, respectively), $F(1,143)=5.61, p<.05, \eta^{2}=0.65$. No main effect of cue valence or stimulus $\times$ cue valence interaction was observed, $F s<2.30, p s>.13$.

These results indicate that the US-expectancy rating for CS1 was higher than that for CS3 and that the ratings decreased across trials, with a decline in the difference between CS1 and CS3 ratings. Compared to the presentation of a hash, presenting a smiley resulted in lower ratings of CS1 and CS3 in the first part of the extinction phase. No differences between the two extinction cue types were observed at the end of the extinction phase, but (at least statistically) CS1 still received higher ratings than CS3.

\section{Renewal test}

The CS ratings for each group are presented in Fig. 3. As CS1 and CS3 were rated differently at the end of the extinction phase, and both renewal and transfer depend on the magnitude of extinction, the last CS1 and CS3 extinction ratings were incorporated as covariates in all the analyses of the renewal data. ${ }^{1}$ Bonferroni corrections were made in case of pairwise comparisons.

Two series of analyses, each focussing on different aspects, were run to analyze the renewal data. In the first series, the data were subdivided into switch/no switch and $(-)$ /\# groups, resulting in 4 separate analyses (i.e., AAA_\# vs. AAA_no\# ABA_\# vs. ABA_no\#, AAA_; vs. AAA_no: $;$, and ABA_- vs. ABA_no: ). Data were analyzed using a GLM repeated measures analysis; in each analysis stimulus (CS1, CS2, and CS3) functioned as a within-subjects factor, and presence vs. absence of the cue as a between-subjects factor. These analyses allowed us to examine the influence of each extinction cue on CS1, CS2, and CS3 responding, in the presence or absence of a context switch.

In the second series, each CS was analyzed separately, but all groups were included, allowing us to examine cue valence and context-switch effects pooled over groups. In this series, univariate analyses of variance were conducted for each CS, with context switch (yes/no) and retrieval cue (absence and presence of $(-)$ or \#) as between-subjects factors. The following pairwise comparisons were included (pooled over the switch and no switch conditions): (1) presence of the $(\dot{)}$ vs. absence of the $\odot ;$; (2) presence of the \# vs. the absence of the \#; (3) presence of the $\odot$ vs. presence of the \#; and (4) absence of the () vs. absence of the \#.

\section{$A A A \_\#$ vs. $A A A \_n o$}

The GLM using the AAA_\# and AAA_no\# data revealed a main effect of stimulus, $F(1.93,71.37)=14.95, p<.001, \eta^{2}=1.00$, and a main effect of cue, $F(1,37)=23.85, p<.001, \eta^{2}=1.00$. No stimulus $\times$ cue interaction effect was observed, $F<1$. Pairwise comparisons indicated that CS2 received higher ratings than CS1 and CS3 did, $p s<.001$, and that no difference was observed between CS1 and CS3, $p=.81$. Presentation of the \# cue clearly resulted in lower CS-ratings.

\section{ABA_\# vs. ABA_no}

The analysis of the ABA_\# and ABA_no\# data revealed a main effect of stimulus, $F(1.92,68.95)=16.52, p<.001, \eta^{2}=1.00$, but no main effect of cue or stimulus $\times$ cue interaction, $F s<1$. Pairwise comparisons indicated that all stimuli were rated differently, $p s<.01$, with CS2 receiving the highest rating, followed by CS1, and CS3.

\footnotetext{
${ }^{1}$ Note that the results were similar if the ratings on the last extinction trial of CS1 and CS3 were subtracted from the renewal test data of CS1 and CS3, respectively.
} 
$A A A_{-}\left(\dot{)} v s . A A A_{-} n o(;)\right.$

The analyses of the no-switch positive cue groups revealed a main effect of stimulus, $F(1.75,54.20)=6.75, p<.005$, $\eta^{2}=0.87$, and a main effect of cue, $F(1,31)=40.31, p<.001, \eta^{2}=1.00$. No stimulus $\times$ cue interaction was observed, $F<1$. Pairwise comparisons indicated that CS2 received higher ratings than CS1 and CS3, $p s<.01$, but no difference was observed between CS1 and CS3, $p=1.00$. Presentation of the cue resulted in a general decrease in CS-ratings.

ABA_: vs. ABA_no:)

The analysis of the ABA_-) and ABA_no $(-)$ groups revealed a main effect of stimulus, $F(1.93,48.46)=7.30, p<.005, \eta^{2}=0.92$, and a nearly-significant effect of cue, $F(1,25)=3.87, p=.06$. No stimulus $\times$ cue interaction was observed, $F<1$. Pairwise comparisons revealed that CS2 received higher ratings than CS3, $p<.005$, and that the other comparisons did not reach significance, $p s>.09$. Although not significant, the cue tended to reduce the rating for all CSs.

Although the stimulus $\times$ cue interaction was not significant, Fig. 2 suggests that in Group ABA_-; , CS1 responding did not differ from responding to CS3, whereas this difference was significant for Group ABA no $\odot$. This was confirmed by separate paired $t$-tests, $t(11)=1.32, p=.22$, and $t(17)=2.30, p<.05$, respectively.

In sum, these results indicate that if no switch in context took place, presentation of the cue resulted in lower CS-ratings, regardless of the type of CS, that the US expectancy was higher after presentation of the non-extinguished CS2 compared to CS1 and CS3, and that there was no differential responding to CS1 and CS3 (near-zero responding). After a context switch, only the $(-)$ tended to reduced CS-ratings; no significant reduction was observed upon presentation of the \#. However, only in the corresponding \#-cue groups were all stimuli rated differently $(\mathrm{CS} 2>\mathrm{CS} 1>\mathrm{CS} 3)$. In Group ABA_no - , omission of the cue resulted in a level of responding to CS1 that did not differ from responding to CS2, whereas ratings for CS1 were higher than for CS3. In the presence of the $(-)$ extinction cue, Group ABA_; , the level of responding to CS1 was decreased to such extent that the difference with CS3 responding was not significant.

\section{CS1 ratings}

An ANOVA focussing on the CS1 rating data revealed a main effect of context switch, $F(1,135)=31.02, p<.001, \eta^{2}=1.00$, extinction cue, $F(3,135)=9.80, p<.001, \eta^{2}=1.00$, and a context switch $\times$ extinction cue interaction, $F(3,135)=3.11, p<.05$, $\eta^{2}=0.71$. Pairwise comparisons revealed that, compared to their absence, the presence of both the $\odot$ and \# reduced CS1 ratings at test, $p s<.05$. No difference between the presence of $(-)$ vs. \#, or the absence of these cues was detected, $p s>.40$.

The context switch $\times$ retrieval cue interaction was caused by a differential effect of the positive and negative cue after a context switch. A separate univariate ANOVA was performed for the \#-groups and $(-)$-groups. In each analysis, CS1 ratings served as the dependent variable, and context switch and cue (present or absent) were used as between-subjects factors. The analysis of the negative cue groups demonstrated a main effect of context switch, $F(1,75)=17.38, p<.001, \eta^{2}=0.98$, and cue, $F(1,75)=6.49, p<.05, \eta^{2}=0.71$, and a context switch $\times$ cue interaction, $F(1,75)=6.10, p<.05, \eta^{2}=0.68$. Further analyses of the interaction indicated that the cue significantly reduced the CS1 ratings (AAA_\# vs. AAA_no\#), $F(1,37)=12.70, p<.005$, $\eta^{2}=0.94$, only when there was no switch in context. No significant effect of cue was observed if a context switch was made (ABA_\# vs. ABA_no\#), $F<1$.

The analysis of the positive cue also revealed a main effect of context switch, $F(1,58)=11.16, p<.005, \eta^{2}=0.91$, and cue, $F(1,58)=19.89, p<.001, \eta^{2}=0.99$, but no significant context switch $\times$ cue interaction, $F(1,58)=2.92, p=.09$.

These results indicate that a context switch resulted in higher CS1 ratings and that, in general, presentation of a cue decreased the ratings. In case of a \# cue, CS1 ratings only decreased if no switch in context took place whereas no such context specificity was observed for the $\odot$ ie.

\section{CS2 ratings}

An ANOVA on the CS2 ratings revealed a main effect of context switch, $F(1,135)=8.12, p<.01, \eta^{2}=0.81$, and extinction cue, $F(3,135)=4.28, p<.01, \eta^{2}=0.86$, but no context switch $\times$ extinction cue interaction, $F(3,135)=1.39, p=.25$. Pairwise comparisons indicated that the presence of the - resulted in lower CS2 ratings compared to its absence, $p<.05$; presentation of the \# compared to no \# did not result in a significant decrease, $p=.10$ (other comparisons, $p s>.50$ ).

\section{CS3 ratings}

For CS3, analyses revealed a main effect of context switch, $F(1,135)=8.73, p<.005, \eta^{2}=0.84$, and extinction cue, $F(3$, $135)=6.01, p<.005, \eta^{2}=0.95$, but no interaction, $F(3,135)=2.00, p=.12$. Pairwise comparisons revealed that only the presence of $\odot$, compared to its absence, significantly reduced the CS3 ratings, $p<.005$; no such effect of the presence vs. absence of the \# was observed, $p=.15$ (other comparisons, $p s>.21$ ).

In sum, these results indicate that, pooled across context-switch conditions, the $\odot$ cue reduced the CS1, CS2, and CS3 ratings, whereas the \# cue only significantly reduced the CS1 ratings. Importantly, the reduction in CS1 ratings due to the presentation of the $(;)$ cue apparently took place irrespective of whether or not a context switch had occurred. Instead, the \# cue only reduced the CS1 ratings in the case when there was no context switch. 
Table 3

Mean ratings $(+S D)$ per group of $\mathrm{CS} 1, \mathrm{CS} 2, \mathrm{CS} 3$, and the US before and/or after the experiment.

\begin{tabular}{|c|c|c|c|c|c|c|c|c|c|c|}
\hline \multirow[t]{3}{*}{ Group } & Before & \multicolumn{9}{|l|}{ After } \\
\hline & \multicolumn{2}{|l|}{ US } & \multicolumn{2}{|l|}{ US } & \multicolumn{2}{|l|}{ CS1 } & \multicolumn{2}{|l|}{ CS2 } & \multicolumn{2}{|l|}{ CS3 } \\
\hline & Pleasant & Startle & Pleasant & $<>$ Startle & Pleasant & Safe & Pleasant & Safe & Pleasant & Safer \\
\hline ABA_- & $1.17(1.21)$ & 6.75 (2.59) & $2.20(1.59)$ & $7.06(1.30)$ & $4.13(1.82)$ & $3.63(2.26)$ & $3.26(1.49)$ & $2.84(1.77)$ & $5.53(2.39)$ & $6.05(2.53)$ \\
\hline ABA_no $\bigodot$ & $1.02(1.55)$ & $5.88(2.29)$ & $1.57(1.37)$ & $7.71(1.64)$ & $4.26(2.40)$ & $4.84(2.48)$ & $3.29(1.79)$ & $3.70(2.16)$ & $5.92(2.26)$ & $6.43(2.25)$ \\
\hline AAA_- & $1.44(.87)$ & $5.03(2.52)$ & $1.58(1.66)$ & $7.01(2.45)$ & $4.81(1.90)$ & $4.95(2.18)$ & $4.12(2.19)$ & $4.59(2.26)$ & $6.96(1.77)$ & $7.15(1.73)$ \\
\hline AAA_no ( & $1.44(1.57)$ & $6.34(2.59)$ & $1.78(1.57)$ & $8.31(1.33)$ & $4.07(2.02)$ & $3.90(2.37)$ & $4.49(2.60)$ & $3.96(2.73)$ & $6.46(1.58)$ & $6.73(1.87)$ \\
\hline ABA_\# & $1.34(1.47)$ & $6.86(2.45)$ & $2.09(1.90)$ & $7.44(2.19)$ & $4.38(2.62)$ & $5.36(2.71)$ & $3.70(1.97)$ & $3.86(2.14)$ & $5.70(2.33)$ & $5.99(2.24)$ \\
\hline ABA_no\# & $1.83(1.32)$ & $6.90(1.75)$ & $1.85(1.78)$ & $7.16(1.29)$ & 4.15 (1.67) & $3.85(1.88)$ & $2.72(1.58)$ & $2.75(2.23)$ & $5.19(1.92)$ & $6.44(2.60)$ \\
\hline AAA_\# & $1.64(.64)$ & $5.59(1.95)$ & $2.36(1.44)$ & $7.72(1.41)$ & $4.92(2.09)$ & $5.66(2.16)$ & $3.84(2.31)$ & $4.53(2.20)$ & $5.27(1.89)$ & $6.21(2.08)$ \\
\hline AAA_no\# & $1.56(1.01)$ & $6.90(1.83)$ & $2.26(1.57)$ & $7.37(1.76)$ & $3.85(2.00)$ & $3.96(2.07)$ & $3.68(2.58)$ & $3.31(2.28)$ & $5.90(2.13)$ & $6.59(2.34)$ \\
\hline
\end{tabular}

Notes. CS: higher scores (range: 0-10) indicate more pleasant and more safe. For the US, higher startle scores indicate stronger subjective startle; <> startle represents the change in startle after the experiment with higher scores representing larger decrease in startle rating (scale: $0=$ strong increase, $5=$ no change, $10=$ strong decrease).

\section{Pleasantness, safety, and startle ratings}

\section{CS pleasantness}

The ratings of the CSs and the US are presented in Table 3. A GLM repeated measures analysis, with stimuli (CS1, CS2, and CS3) as a within-subjects factor and cue valence (positive vs. negative cue present during the extinction) as a betweensubjects factor, was carried out. This analysis revealed a main effect of stimulus, $F(1.89,268.05)=47.61, p<.001, \eta^{2}=1.00$, a marginally significant effect of cue valence, $F(1,142)=3.31, p=.071, \eta^{2}=0.44$, but no interaction, $F(1.88,268.05)=1.05, p=.35$. Pairwise comparisons indicated that CS3 was rated as more pleasant than CS1, and that CS1 was rated as more pleasant than CS2 $($ CS3 $>$ CS1 $>$ CS2 $), p s<.01$. Presentation of the $:-$ cue during the experiment tended to result in more positive ratings than presentation of the \# cue did.

\section{CS safety}

A similar analysis was run for the safety data. This analysis also revealed a main effect of stimulus, $F(1.85,264.35)=62.28$, $p<.001, \eta^{2}=1.00$, but no effect of valence or stimulus $\times$ valence interaction, $F s<1$. Pairwise comparisons indicated that CS3 was rated as more safe than CS1, and that CS1 was rated safer than CS2 $(\mathrm{CS} 3>\operatorname{CS} 1>\mathrm{CS} 2), p s<.01$.

\section{US ratings}

An ANOVA with rating time (before or after experiment) as a within-subjects factor and valence as a between-subjects factor was carried out on the US pleasantness ratings. This analyses revealed a main effect of rating time, $F(1,142)=19.10$, $p<.001, \eta^{2}=0.99$, but no main effect of valence or of the rating time $\times$ valence interaction, $F s<2.99, p s>.085$. There was no difference between the eight groups in US-startle rating before the acquisition phase, $F(7,144)=1,93, p=.07$ (all multiple comparisons, $p s>.19$ ). At the end of the experiment, the level of the startle evoked by the US was significantly reduced compared to the initial startle level (i.e., the startle change score was significantly higher than 5 ), $t(144)=16.94, p<.001$. The change score did not differ between the $(-)$ and \# groups, $F<1$.

The rating data indicate that the level of experienced pleasure and safety of the CSs can be summarized as: CS3 $>$ CS1 > CS2 . Presentation of the $:)$ during extinction tended to increase the pleasantness of the ratings. The repeated presentation of the US resulted in higher, more positive, pleasantness ratings and a decrease in startle rating. Note that although the pleasantness ratings increased, the US was still rated as highly unpleasant after the experiment (mean: 1.94, SD: 0.13).

\section{Discussion}

In the present experiment, participants first learned that two CSs were associated with an aversive auditory US, whereas a third stimulus was not. Subsequently, they learned that one of the previously reinforced CSs was no longer followed by the US, while the non-reinforced CS continued to be non-reinforced. This extinction learning took place against either the acquisition background color context or against a new background color context and in the presence of a positive or negative distinct extinction cue. Importantly, upon their first presentation during this extinction phase, differential responding to the previously reinforced and non-reinforced CSs was still intact, regardless of the valence of the extinction cue and whether or not a context switch had occurred. This suggests that generalization decrement, which was observed, was not sufficient to undermine the previously learned discrimination between reinforced and non-reinforced CSs. During extinction, the presence of the positively valued cue had a beneficial effect on extinction of responding to the previously reinforced CS, relative to the presence of the negatively valued extinction cue. However, in both cases, extinction was successful, with near-zero CRs at the end of extinction (although the difference between the previously reinforced and non-reinforced CS statistically was still significant). Most importantly, however, during the subsequent test, the positive cue, but not the 
negative cue, reduced the level of renewed conditioned responding to the extinguished CS (increase in US expectancy rating) that was induced by a switch from the extinction context back to the acquisition context. In effect, the positive cue not only reduced renewal of responding to the extinguished CS, but also decreased the expectancy ratings of the consistently reinforced and non-reinforced CSs.

Responding to the consistently non-reinforced CS3 in the context-switch/cue-present groups (Groups ABA_(-),and ABA_\#, the groups only experiencing a change in context from extinction to test) clearly increased from the last extinction session to the renewal test (compare Figs. 2 and 3, paired $t$-tests, $t s<-3.28, p s<.01$ ). This suggests that either the acquisition background had excitatory properties and/or that the context switch caused generalization decrement. However, CS2 (the consistently reinforced CS) still evoked higher expectancy ratings than CS3 (the consistently non-reinforced CS) in both these groups, despite the influence of these more general effects. The discrimination between CS1 (trained and extinguished CS) and CS3 too was still intact in Group ABA_\#, indicating renewal despite the putative general effects. However, this CS1/CS3 discrimination was not present in Group ABA_; , which supports the conclusion of a relatively strong inhibitory potential of the positive extinction cue.

That the positive cue was able to decrease the expectancy ratings for all CSs, even in the case of a context switch, is indicative of that cue functioning as a conditioned inhibitor. When no context switch had occurred between extinction and testing, both the positive and the negative cues were able to reduce the expectancy ratings of all CSs, thereby suggesting their role as conditioned inhibitors in this case.

The pleasantness and safety ratings of the stimuli were in accordance with their predictive value. The stimulus that was never followed by the US was rated as most positive and safe, and the stimulus that was not extinguished received the lowest ratings. The extinguished CS was rated in-between the aforementioned CSs. Most importantly, the positively valued cue increased the pleasantness of the CSs. This might indicate that the positive cue transferred its value to the other stimuli presented during the experiment.

Dibbets et al. (2008) performed an experiment that strongly resembles the present study. In that study an ampersand (\&) served as the extinction cue. In the pilot study in which we examined the affective value of various symbols (described in Section Methods), the '\&' received a mean rating of 59.4 (SD: 16.5), suggesting that it was a neutral cue, with an affective value in-between that of the negative (38.1) and positive (87.5) cues used in the present experiment. In the previous study, the ' $\&$ ' extinction cue was found to decrease the US-expectancy rating of the extinguished CS, but not of the consistently reinforced and non-reinforced CSs. This suggests that only the ' $\&$ ' functioned as a true 'retrieval cue' or occasion setter that specifically signals, or brings to memory, the CS-no US association for the trained-and-extinguished cue (Bouton, 1994).

The picture that seems to emerge from the combined results of the two studies is that extinction background color contexts and more punctuate and variable, non-static (with respect to location) extinction cues, compete for inhibitory control over the CS. Loosely speaking, at least with the stimuli used in our experiment, in the case of a context switch and a negative cue, the context is held responsible for the non-occurrence of the US that was expected to be presented on the basis of the previous training phase. In this case, the context completely overshadows the cue with respect to the acquisition of inhibitory properties. In the case of a neutral cue, the context does not overshadow the extinction cue. However, the inhibitory properties acquired by the cue are limited in that they only apply to the trained-and-extinguished CS (i.e., the cue functions as an occasion setter). Finally, in the case of a positive cue, the context is completely unable to overshadow the CS, which acquires 'full' inhibitory properties, serving as a true safety signal for all types of CSs.

The picture looks different if the context remains constant throughout, as in the AAA groups. Here, any cue, regardless of its valence, can be considered to receive full attention and, hence, becomes associated with the absence of the US in general, implying conditioned inhibitory properties.

Regardless of the validity of these theoretical considerations, the empirical findings might have implications for exposure treatments, perhaps especially when these treatments focus on changing existing cognitions and expectations concerning fear-provoking conditioned stimuli. As already indicated in the introduction, one could argue that an ideal, clinically most useful, extinction cue is a cue that: (1) can suppress conditioned responding to all possible stimuli functioning as CSs, while (2) it does not result in 'protection from extinction' with respect to target CSs (i.e., the CSs explicitly used as targets for the clinical intervention), which would imply a return of undesirable behavior when the cue is absent. However, these two requirements might be incompatible for both theoretical and practical reasons. The first requirement can be fulfilled if the extinction cue serves as a conditioned inhibitor or 'safety signal'. Conditions that are conducive to achieving this are the use of positive cues, especially when they are presented throughout the extinction phase and simultaneous with the target CS (rather than when the cue and target CS are presented serially and when the cue is presented irregularly, e.g., Brooks \& Bouton, 1994). However, when an extinction cue acquires conditioned inhibitory properties, it can protect the to-be extinguished CS from extinction (e.g., Lovibond et al., 2000), which is not in line with the second requirement. One way in which the second requirement might be fulfilled is using extinction parameters and cues that are favorable for the development of occasion-setting or retrieval-cue properties by the extinction cue. These include performing the exposure or extinction treatment in the same context as the acquisition context, in combination with the use of a relatively neutral stimulus, which is now-and-then presented prior to the target CS (e.g., Brooks \& Bouton, 1994). In this way, the cue might become part of the extinction context (without acquiring simple excitatory or inhibitory properties) that may later help the participant to retrieve a memory of the extinction episode under conditions when this episode is not otherwise activated (e.g., by other contextual cues). These treatment parameters might also imply little hindrance of extinction of the target CS-US association (no protection from extinction). However, one well-known feature of (negative) occasion setters or retrieval 
cues is that they have the tendency to only attenuate conditioned responding to CSs that were presented during extinction (Bouton, 1991). This feature undermines the usefulness of presenting the cue as a general means to attenuate conditioned responding to other potential CSs that were not part of the intervention program, which runs counter the first requirement.

Presumably, most clinical treatments take place in a setting that is different from the therapeutic context in at least some respects, which greatly enhances the chance of the expression of extinction becoming dependent on the presence of specific contextual cues. In other words, the expression of the CS-no US association that is learned in extinction will come under the control of these contextual cues and, in this sense, there is no real elimination of the CS-US association. Given that in practice it might be difficult to prevent such protection from extinction in any case, it might be useful to consider using more-or-less discrete extinction cues that come to function as conditioned inhibitors or safety signals. When needed, such signals could then perhaps more easily be controlled and applied by the patient than is the case for more diffuse contextual stimuli. A discrete safety signal would also have the additional benefit of having the potential to attenuate responding to other CSs that were not explicitly targeted during the treatment. The present study suggests that positive cues might be especially suitable for this purpose and might even decrease the negative valence of conditioned stimuli next to reducing expectancies for future aversive events. However, future research should examine whether explicit extinction training in the presence of such positively valued cues is necessary to provide them with additional inhibitory properties over and above the inhibitory capacities that they already have acquired outside of the context of the experiment. For example, one could compare the level of renewal between a condition receiving the positive cue for the first time at test and a condition receiving the cue during both extinction and testing (as in Group ABA_:) ).

Of course, the present study does have a number of limitations. We only measured US expectancy; no physiologic measures were taken. This makes it more difficult to interpret the results in terms of fear conditioning and exposure treatment. Additionally, the US was rated as less unpleasant and less startle was evoked after repeated presentation, indicative of habituation. Another limitation is the use of a background color as 'context', which could be argued to be qualitatively different from 'real', multi-dimensional environmental contexts. Finally, as we only tested students without anxiety problems, it is difficult to generalize the results to a (sub)clinical population. In the future it would be highly interesting to examine the influence of a (positive) extinction cue in an anxious population, incorporating physiologic measures, using a stronger US, and more real-life environmental contexts and extinction cues.

\section{Acknowledgments}

We would like to thank Anouk Janssen, Jenneke van Genechten, Frank Strikers, and Peter Verschuren for their contribution to this study.

\section{References}

Bishop, S. J. (2007). Neurocognitive mechanisms of anxiety: An integrative account. Trends in Cognitive Sciences, 11, 307-316.

Bouton, M. E. (1991). Context and retrieval in extinction and in other examples of interference in simple associative learning. In L. Dachowski, \& C. F. Flaherty (Eds.), Current topics in animal learning: Brain, emotion, and cognition (pp. 25-53). Hillsdale, NJ: Erlbaum.

Bouton, M. E. (1994). Conditioning, remembering, and forgetting. Journal of Experimental Psychology: Animal Behavioral Processes, 20, $219-231$.

Bouton, M. E. (2002). Context, ambiguity, and unlearning: Sources of relapse after behavioral extinction. Biological Psychiatry, 52, $976-986$.

Bouton, M. E. (2004). Context and behavioral processes in extinction. Learning and Memory, 11, 485-494.

Brooks, D. C., \& Bouton, M. E. (1994). A retrieval cue for extinction attenuates response recovery (renewal) caused by a return to the conditioning context. Journal of Experimental Psychology: Animal Behavior Processes, 20(4), 366-379.

Brooks, D. C., Vaughn, J. M., Freeman, A. J., \& Woods, A. M. (2004). An extinction cue reduces spontaneous recovery of ataxic ethanol tolerance in rats. Psychopharmacology, 176, 256-265.

Collins, B. N., \& Brandon, T. H. (2002). Effects of extinction context and retrieval cues on alcohol cue reactivity among nonalcoholic drinkers. Journal of Consulting and Clinical Psychology, 70, 390-397.

Creamer, M., Foran, J., \& Bell, R. (1995). The Beck Anxiety Inventory in a non-clinical sample. Behaviour Research and Therapy, 33, 477-485.

Dibbets, P., Havermans, R., \& Arntz, A. (2008). All we need is a cue to remember: The effect of an extinction cue on renewal. Behaviour Research and Therapy, 46, 1070-1077.

Hamm, A. O., Vaitl, D., \& Lang, P. J. (1989). Fear conditioning, meaning, and belongingness: A selective association analysis. Journal of Abnormal Psychology, 98, 395-406.

Havermans, R. C., \& Jansen, A. T. M. (2003). Increasing the efficacy of cue exposure treatment in preventing relapse of addictive behavior. Addictive Behaviors, $28,989-994$.

Holland, P. C. (1983). Occasion-setting in Pavlovian feature positive discriminations. In M. L. Commons, R. J. Herrnstein, \& A. R. Wagner (Eds.), Quantitative analyses of behavior: Discrimination processes (pp. 183-206). New York: Ballinger.

Holland, P. C. (1989). Transfer of negative occasion setting and conditioned inhibition across conditioned and unconditioned stimuli. Journal of Experimental Psychology: Animal Behavior Processes, 15, 311-328.

Lanzetta, J. T., \& Orr, S. P. (1986). Excitatory strength of expressive faces: Effects of happy and fear expressions and context on the extinction of a conditioned fear response. Journal of Personality and Social Psychology, 50, 190-194.

Lovibond, P. F., Davis, N. R., \& O'Flaherty, A. S. (2000). Protection from extinction in human fear conditioning. Behaviour Research and Therapy, 38, 967-983.

Marks, I. M., Hodgson, R., \& Rachman, S. (1975). Treatment of chronic obsessive-compulsive neurosis by in-vivo exposure: A two-year follow-up and issues in treatment. British Journal of Psychiatry, 127, 349-364.

McHugo, G. J., \& Smith, C. A. (1996). The power of faces: A review of John T. Lanzetta's research on facial expression and emotion. Motivation and Emotion, $20,85-120$.

Mowrer, O. H. (1939). A stimulus-response analysis of anxiety and its role as a reinforcing agent. Psychological Review, 46, 553-565.

Öst, L. G. (1989). One-session treatment for specific phobias. Behaviour Research and Therapy, 27, 1-7.

Öst, L. G. (1996). One-session group treatment of spider phobia. Behaviour Research and Therapy, 34, 707-715.

Öst, L. G. (1997). Rapid treatment of specific phobias. In G. C. L. Davey (Ed.), Phobias: A handbook of theory, research and treatment (pp. 227-246). Chichester, England: John Wiley \& Sons. 
Pavlov, I. (1927). Conditioned reflexes. London: Oxford University Press.

Van der Ploeg, H. M. (1982). De zelf-beoordelings vragenlijst (STAI-DY). Tijdschrift voor Psychiatrie, 24, 576-588.

Vansteenwegen, D., Vervliet, B., Hermans, D., Beckers, T., Baeyens, F., \& Eelen, P. (2006). Stronger renewal in human fear conditioning when tested with an acquisition retrieval cue than with an extinction retrieval cue. Behaviour Research and Therapy, 44, 1717-1725.

Watson, J. B., \& Rayner, R. (1920). Conditioned emotional reactions. Journal of Experimental Psychology, 3, 1-14. 